\title{
The Operating Characteristics of Intercity Public Van Service in Lampung, Indonesia
}

\author{
Sulistyo Arintono \\ Universiti Putra Malaysia
}

\begin{abstract}
The business of providing pickup and delivery service for intercity passengers flourishes in Indonesia. In Lampung Province, it is available to popular destinations, including Jakarta, Palembang, and Bakauheni. To date, there is no detailed information regarding operating characteristics, highlighting the importance of this research for future reference. The data for analysis were collected through a series of field surveys on service frequency and passenger and driver interviews conducted at the ferry terminal of Bakauheni. Results of the analysis suggest that there are too many vehicles operating on the Bandar Lampung-Bakauheni route. The implications are that the total number of trips, the number of passengers carried, and crew income per vehicle per day are limited. The vehicle queuing and dispatching system needs to be improved to prevent passengers from waiting too long. The conclusion is that this business is profitable only if there is a good operating arrangement.
\end{abstract}

\section{Introduction}

Pickup and delivery service for intercity passengers enjoys increasing demand in Indonesia. This is due to the relatively low level of private vehicle ownership and the improved socio-economic status of the population where a higher level of transport service is demanded but cannot be met by the existing public transport 
services. To date, there is limited data, if any, regarding the operating characteristics of pick-up and delivery service vehicles for intercity travel (locally known as "travel vehicles").

In Bandar Lampung, the capital city of Lampung Province in western Indonesia, there are a number of small private firms offering intercity passenger service other than bus. Among the most popular destinations are Jakarta (the national capital, $200 \mathrm{~km}$ to the east), Palembang (the capital city of the Province of South Sumatra, $300 \mathrm{~km}$ to the north) and Bakauheni (a ferry crossing port linking the islands of Sumatra and Java, $100 \mathrm{~km}$ to the east). Being a door-to-door service, a passenger can make a telephone call to one of the service providers and be picked up and delivered to his/her final destination without the need to transfer to any other mode(s) of transport. This is what makes the travel service superior to ordinary public transport, and there is room for further improvement since customers are willing to pay more for a better level of service.

Previous research by Arifianto (2003) does not discuss sufficient details of the operating characteristics of such service, but merely conducts a cost-revenue analysis in general. This current research is expected to contribute to the transport system database in the province, as well as to improved operating conditions and level of service for the benefit of both operators and users.

\section{Research Methodology}

In Bandar Lampung, travel service companies normally have their own schedule of departure for their vehicles. Depending on the destination and the demand for that particular route, the intervals between successive departures of the same route vary from, for example, once an hour to twice within a day. These schedules are not coordinated among the service providers, so a potential customer should shop around to find the most appropriate time of departure to fit his/her need. Unfortunately, it is not unusual for an already-scheduled departure to be delayed because of lack of customer demand. For these reasons, observation of departures and arrivals was not conducted at the dispatching points scattered around the city, but concentrated in Bakauheni, an inter-island ferry terminal between Java and Sumatra, the busiest destination in terms of travel operation within the province.

Data concerning the operating characteristics of the travel vehicles were collected through a series of surveys in Bakauheni, including observation of the arrival and departure times of vehicles, departing arrangements by the port authority, and 
interviews with drivers and passengers. Surveyors were assigned to record vehicle registration numbers, arrival or departure times, and number of passengers carried, continuously for 24 hours for 3 days ( $3 \times 24$ ). The length of observation was specifically designed to get a sufficient number of cycle times, since from the previous research by Arifianto (2003) it was known that not all vehicles operate on a daily basis. A similar case occurs in bus operations on the route of Rajabasa-Bakauheni because there are too many buses, well over the required number (Chandradewi 2003; Tjikasan 2003).

Another team of surveyors conducted the driver and passenger interviews, which were done at a convenient time and place within the passenger terminal of the port. Interviews with passengers were intended to gather data regarding passenger characteristics such as gender, age, marital status, level of education, occupation, purpose of trip, frequency of using the travel service (per week or per month), etc., which may be useful for demand analysis. Similar interviews with drivers were administered with slightly different questions to include main occupation other than driving travel vehicle, number of working days per week, monthly take-home pay, etc. A total of 50 drivers and 50 passengers, well above the minimum target of 30 individuals each for a reliable statistical analysis, were successfully interviewed.

There were complaints that travel vehicles usually run fast, disobeying the standard procedures for safe driving and, therefore, risking passengers onboard, so an additional survey was designed to check the average travel speed of the vehicles. For this purpose, observers were located in Panjang, roughly $20 \mathrm{~km}$ prior to reaching the Bandar Lampung city centre, where travel vehicles start to deviate their routes due to different passenger destinations, to record vehicle registration numbers and their passing times. Since the departure times of all travel vehicles from Bakauheni were recorded by the other team of surveyors, it was possible to calculate the average travel speed between Bakauheni and the respective observation point.

\section{Data Analysis}

From the data collected during the survey, several performance indicators were computed, consisting of number of trips per vehicle per day, travel distance per vehicle per day, number of passengers carried per trip, number of passengers carried per vehicle per day, travel time, cycle time, queuing time, service headway, required number of vehicles, etc. In addition, based on the interviews and 
observation of the whole operation, driver and passenger characteristics, as well as the operating characteristics of the vehicles, can be clearly described. However, the main discussion in this paper is about the operating characteristics of the vehicles.

\section{Driver Characteristics}

Driver interviews revealed that most drivers (58\%) are aged 31-40 years, typical of the major workforce within any community; educated to senior high school (98\%); married (96\%); and working as a driver as their major source of income (100\%) for seven days per week (48\%), with an average monthly earning of roughly Rp600-700,000.00 per month. These conditions do not differ significantly from the characteristics of drivers of other types of public transport vehicles. The fact that they fully rely on driving for a living, while the average take-home-pay is even less than the 1999 level (Rp40,000.00 per day, as discussed by Arintono 2001 and Arintono 2003), reflects severe competition and high operating inefficiency. If they had more spare time, they might spend it on other productive activities.

\section{Passenger Characteristics}

Based on the interviews with 50 travel passengers, most were male (66\%), 21-30 years of age (30\%), not married (68\%), educated to senior high school $(44 \%)$ or university graduate $(42 \%)$, self-employed $(32 \%)$ or employed by a private company (32\%), with an average income of over Rp1,000,000.00 per month (38\%). The socio-economic status of passengers is just slightly higher than that of drivers, which implies that there could be more demand if service quality improves.

\section{Trip Characteristics}

The majority of passengers use the travel service on a non-regular basis (50\%), and about 36 percent travel between the origin and destination points regularly once or twice a month. In terms of the purpose of the trip, 54 percent make it for social visits, and almost all of them are more or less satisfied with the service provided. There are some complaints regarding the delivery of passengers to their final destinations, which is not in good order (22\%) and the tendency of the crew to drive the vehicle too fast (20\%).

\section{Vehicle Operating Characteristics}

Distinct from the other public transport vehicles in Indonesia (bus, taxi, mikrolet, and truck), which have registration plates that are yellow with black letters, travel vehicles operating in Lampung Province have special registration plates that are black with white letters, similar to private vehicles. Normally, the numbering starts 
with two letters ( $B E$, the same for all vehicles registered in Lampung Province) followed by four digits and two letters, indicating the district in which a particular vehicle is registered within the province (for example, BE 2956 LA). Special for travel vehicles are the last two letters, RS, for "Ranmor Sewa" or "Hired Vehicle" to declare that they are actually public transport vehicles.

The vehicles used are usually minibuses of popular models in the country such as an Isuzu Panther, a Toyota Kijang, a Mitsubishi Kuda, or a Mitsubishi L-300. All minibuses have an 8-seat capacity except the Mitsubishi L-300, which can accommodate up to 10 adult passengers. There are 128 registered vehicles operating on this route with 171 drivers. However, during the 3x24-hour survey, only 124 vehicles were observed. Detailed information on company name, number of vehicles operated, and number of drivers is shown in Table 1.

Table 1. Travel Vehicle Distribution by Company

\begin{tabular}{lcc}
\hline Company Name & No. of Vehicles & No. of Drivers \\
\hline Purnagama & 27 & 37 \\
Wijaya Kesuma & 27 & 37 \\
Ananda & 19 & 27 \\
ASDP & 9 & 12 \\
Lampung Surya & 13 & 18 \\
Ramayana 8181 & 13 & 14 \\
Karona & 8 & 9 \\
Tegas & 12 & 17 \\
\hline Total & $\mathbf{1 2 8}$ & $\mathbf{1 7 1}$ \\
\hline
\end{tabular}

Source: Calter (2006)

In the ferry terminal of Bakauheni, each travel company has its own dispatching point alongside other companies. Therefore, there are always eight vehicles ready to depart at any time once they are fully loaded. The intending passengers do not know which of the eight vehicles will depart first. The common practice is that drivers of other vehicles of the same company (who are queuing) take the empty seats, pretending to be passengers to show that the vehicle is almost full to attract passengers since the vehicles will depart only when all seats are occupied. This dispatching arrangement causes passengers to wait for a long time since the limited number of passengers is distributed among eight vehicles, and thus the departures of all vehicles are sufficiently delayed.

The only good thing about this kind of practice is that passengers are free to select their own preferred vehicle, e.g., the new and clean vehicle with good service as 
recommended by their family or friends. They do not have to take the first vehicle in the queue as in the single queue system, since the vehicle may be an old and dirty one and is not recommended because of bad service.

Switching the queue system from single to multiple occurred at the Jakarta International Airport taxi operation. Previously, Blue Bird was the only taxi company that could legally carry passengers out of the airport. Later, other taxi companies demanded that the system be open to all companies with no limitations. Following this demand, the airport authority applied an open system with a single queue in which intending passengers were to take the first taxi in the queue. However, passengers had their own preferences when selecting a taxi to ride; among the locals and well-informed visitors, Blue Bird was at the top of the list. Thus, there were protests from users against the single queuing system, as many of them could not get their favorite taxi and were forced to take a taxi with a bad reputation. After many complaints through newspapers and other media, the queuing system was again altered. Since then, every taxi company has its own queue line, and passengers once again have the option to choose. Clearly, this change has benefitted both the taxi operators (for access to carry passengers out of the airport) and passengers (for retaining the freedom to choose).

The case of travel vehicles at the Bakauheni ferry terminal is slightly different. First, unlike taxis, which are exclusively-hired vehicles (passengers are groups of people who travel together for a single destination), travel passengers can be people who are not familiar with one another and have multiple destinations. For this reason, they have to wait much longer to depart until the vehicle is full (8 persons) compared to taxi (3-4 persons). Second, no travel company is significantly superior to others in terms of service quality. No matter what vehicle a passenger chooses, he/ she will get more or less the same level of service as offered by other vehicles. In this respect, there is no benefit to having a multiple queue system in which passengers have to wait much longer for departure.

Some vehicles do not join the queue for two reasons: first, they are requested by the company to return to Bandar Lampung because there is no vehicle left for the next departure, and second, the driver is not patient enough to wait for a long queue. The vehicles that do not go through the queue, however, will not depart empty, but rather will carry passengers already in another vehicle of the same company (from the dispatching point). The general agreement between the drivers is that they will carry no more than four passengers, and the driver of the vehicle in the queue will receive some compensation. 
While vehicles departing from Bakauheni are always fully occupied (except those departing earlier not through the queue), the same does not apply to vehicles departing from Bandar Lampung. In many cases, the vehicles have to be dispatched even when there are empty seats, because some of the passengers have been waiting too long. The driver always will try to fill up these empty seats on the way to Bakauheni, in which case the money collected from the additional passengers will go into his own pocket. This is actually against regulations, since the travel vehicle is not a "taxi," which can be for hire on the streets, but this is the normal practice. For this purpose, travel vehicle drivers search for extra passengers around Panjang, a small town located roughly 20 kilometers to the east of Bandar Lampung.

In addition to officially-registered travel vehicles (with RS letters at the end of their registration numbers), "black travel" vehicles also operate along this profitable route of Bandar Lampung-Bakauheni. Due to the similarity of the vehicles (the only difference being the RS code on the registration plate), intending passengers are not aware if they take a "black" (illegal) travel vehicle.

Logically, pickup and delivery of passengers should follow a certain order to save time and gasoline. For example, it should start from passengers farthest away from the company office, then pick up the nearer ones. But passengers cannot expect this proper procedure to prevail. In some cases, and especially for travel vehicles departing from Bakauheni, since the drivers do not record the final destination of individual passengers before starting the journey, passengers complain that they are brought round and round in the city streets without knowing their turn to be delivered to their intended address. In addition to this inconvenient experience, the drivers also ask for extra payment, citing the extra distance to be traveled. The official fare was Rp18,000.00 per passenger trip prior to the fuel price increase of October 1, 2005 (when the fare was then increased to Rp30,000.00). However, the drivers usually charged $\mathrm{Rp} 25,000.00$ or higher. If the passengers do not pay, they are not delivered to their destination. This is an often-heard complaint.

\section{Number of Trips and Passengers}

During the three-day period of observation, 474 trips were recorded either entering or leaving the ferry terminal of Bakauheni. As the number of operating vehicles (indicated by the registration number) was 124 units, the total number of trips per vehicle per day was 1.27 . Observation on the number of passengers recorded 3,553 persons for the trips made during the three-day period, an average of 7.49 passengers per trip. This further reveals 9.5 passengers per vehicle per day, with an average load factor of 93.63 percent per trip. It is suspected that this extremely low 
number of passengers carried may not be able to balance vehicle operating costs, indicating that travel vehicle operation is at a loss.

\section{Service Frequency and Headway}

The pickup and delivery service at the dispatching point in Bakauheni runs 24 hours a day, 7 days a week. Travel vehicles leave the ferry terminal with minimum, maximum, and average headways of 3, 27 and 15 minutes, respectively (four departures per hour). The last vehicle leaves Bandar Lampung at about 22:00, and the first vehicle departs at 06:00. With an average travel time of two hours from Bandar Lampung to Bakauheni, there is no arrival to the ferry terminal between 00:00 (midnight) and 08:00. Meanwhile, the minimum, maximum, and average arrival headways are 2, 24 and 10 minutes, respectively (six arrivals per hour). However, these headways do not necessarily reflect passenger waiting time due to the multiple queuing system.

\section{Cycle Time and Queue Time}

From the record of the registration numbers of the arriving and departing vehicles at the ferry terminal, cycle time and queue time can be computed. Table 2 shows cycle time based on observation of either arrival or departure times.

Table 2. Cycle Time

\begin{tabular}{lc}
\hline Basis of Calculation & Cycle Time (hours) \\
\hline Arrival Time & \\
Minimum & 19.45 \\
Average & 25.34 \\
Maximum & 31.70 \\
Departure Time & \\
Minimum & 13.55 \\
Average & 25.92 \\
Maximum & 39.12 \\
\hline Grand Average & $\mathbf{2 5 . 6 3}$ \\
\hline
\end{tabular}

Queue time is defined as the difference between the arrival time of a particular vehicle at the ferry terminal and the departure time of the same vehicle from the terminal. This queue time includes break times for drivers plus waiting time at the dispatching point until the vehicle is fully loaded. Results of the analysis suggests that the actual queue time ranges from 2.67 hours (minimum) to 5.17 hours (maximum), with an average of 3.95 hours. A reasonable break time is normally considered as 10-15 percent of work time (travel time for drivers). 
As discussed earlier, the average travel time between Bandar Lampung and Bakauheni is around two hours one way, plus another three hours for the pickup and delivery of passengers in the city; the total driving task is seven hours ( 420 minutes) per cycle. The associated reasonable break time lies between 42-63 minutes. Assuming that a 60 -minute break is average, a reasonable cycle time becomes 8 hours. It is clear from this exercise that the existing cycle time (25.63 hours) and queue time (which also functions as break time for drivers, 3.95 hours) are too long, indicating inefficiency in travel vehicle operation.

\section{Fleet Size}

Normally, in public transport operation, the required fleet size is computed by dividing the cycle time by the headway. For a general public transport vehicle serving two end terminals, the cycle time is calculated based on travel time plus break time, not the observed cycle time (especially when the total number of operating vehicles are too many, resulting in an excessively long cycle time). On the other hand, the minimum headway is chosen so that the fleet size is sufficient to serve passenger demand during peak time. However, this method is not applicable to calculate the required fleet size of travel vehicles on the route of Bandar Lampung-Bakauheni since the short minimum headway does not reflect peak passenger demand. Rather, it happens because of the uncoordinated departure of the vehicles within the existing companies, meaning that some vehicles are fully loaded at almost the same time, resulting in short headway (three minutes). As such, the grand average ( 12.5 minutes) between headways, based on arrival time (10 minutes) and departure time (15 minutes), and the calculated cycle time ( 8 hours) are taken as the basis of the analysis to determine the required fleet size. The resulting figure is 43 vehicles, including 10 percent spare, well below the existing number of 128.

\section{Proposed Improved Efficiency}

The significantly higher number of operating vehicles than required results in extremely low use of every vehicle. As discussed earlier, each vehicle can make only 1.27 trips carrying 9.5 passengers per day - not even a round trip, which could be considered as the minimum expected turn over - showing that all vehicles are highly underused. This phenomenon is also evident in the other types of public transport vehicles operating within the province, as discussed in Arintono (2008) for motorcycle taxi and Arintono (2001) for mikrolet (10-14 seat capacity minibus).

To improve vehicle operating efficiency, the following arrangements are proposed: 
- The queuing system should be changed from multiple to single, based on arrival time and irrespective of the company name of the vehicles. This will reduce passenger waiting time to 15 minutes maximum.

- Vehicle operations should be arranged into three shifts, where every vehicle is allocated one day "on" followed by two days "off," given that the total number of existing vehicles (128) is almost exactly three times the required number (43).

Table 3 shows several indicators of the improved efficiency if the operating fleet size were to be controlled at the reasonable level.

Table 3. Improved Efficiency in Travel Operation

\begin{tabular}{lcc}
\hline \multirow{2}{*}{ Remarks } & \multicolumn{2}{c}{ Operating Conditions } \\
\cline { 2 - 3 } & Existing & Proposed \\
\hline Queuing system & Multiple & Single \\
Shift schedule (1 day on 2 days off) & Not applied & Applied \\
Number of vehicles & 128 & 43 \\
Trips/vehicle/day & 1.27 & 3.67 \\
Passengers/vehicle/day & 9.51 & 27.49 \\
Cycle time (hours) & 25.63 & 8.00 \\
Passenger waiting time (minutes) & Unpredictable & 15 min (max) \\
Driver queuing time (hours) & 3.95 & 1.00 \\
\hline
\end{tabular}

In Table 3, the number of trips per vehicle per day and the number of passengers per vehicle per day are calculated based on the existing demand for the multiple queue system where passenger waiting time is unpredictable. If the queuing system were altered from multiple to single, the average waiting time is reduced to 15 minutes, equal to the average departure headway. This is short enough to attract additional demand for the travel service, and therefore the total number of trips and the number of passengers carried per vehicle per day will increase, which, in turn, will decrease passenger waiting time even further.

There may be reluctance from existing drivers to follow the new "on and off" system, considering that their income will be even more limited. So a persuasive effort should be made to make them aware that the new system will be to their benefit. Initially, average vehicle use (e.g., total vehicle-kilometer per vehicle per day) will remain constant with either the multiple or the single queue system, but the utilized and non-utilized hours will be more organized in the single queue system with the "on and off" arrangement. Moreover, drivers will not need to spend 
long waiting times at the ferry terminal, and the non-working days can be spent for more useful and productive purposes.

A problem remains in the other side of the route, in Bandar Lampung, where every company has its own dispatching points scattered around the city. Intending passengers do not know which operator to select to get to Bakauheni at certain time of the day. If, and only if, all eight travel operators can set up a central booking office and distribute the demand properly and fairly, then potential passengers will benefit much from the new system. They will not have to shop around any more, and they can be sure to be picked up and delivered to Bakauheni as scheduled.

A somewhat similar system is practiced (though not officially declared) in Palembang. There, a number of travel companies offer intercity passenger service between Palembang and Bandar Lampung. Due to low demand and an excessive number of vehicles, usually only a very few companies (if any) dispatch their vehicles with a reasonable number of passengers onboard. The solution is for them to combine passengers from many dispatch points and transport them to their destination (Bandar Lampung) using a number of vehicles based on mutual agreement among themselves. Because of this practice, passengers are sacrificed in terms of the long waiting time (while the deal is being settled), and the ordered seating arrangement becomes invalid. It suggests that these travel companies need to coordinate their services to make the whole operation more efficient. In fact, they manage to do it to a certain extent. It will improve the existing system if they set up a central booking office to be run and financed by all the parties concerned.

Regarding the switch from a multiple to a single queue system, it may be opposed by the port authority since they have interest in this travel operation, as shown by the fact that one of the registered travel companies (ASDP) is owned by the port authority. However, observation indicates that none of them is more in demand than others, suggesting that all vehicles suffer from extremely low utilization. Therefore, there is good reason to implement the single queue system with the following benefits:

- Less space required for the dispatch point and parking of vehicles in queue

- Fewer vehicles in circulation required, implying potential for other use

- Smoother circulation of passengers within the terminal building

- Impression that the port authority is applying a "level playing field" in doing business in the transport industry 


\section{Conclusions and Recommendations}

The general tendency in public transport operation in Indonesia - that the number of operating vehicles exceeds the required number, leading to low operating performance, as indicated by long cycle and queue times, limited vehicle utilization, and low number of passengers carried, resulting in limited driver income - is also evidenced in travel vehicle operation.

To improve the operating environment to benefit both users and operators, the queuing system needs to be changed from a multiple-queue to a singlequeue system based on vehicle arrival time and irrespective of the company affiliation of the vehicles. A shift scheduling of one day on and two days off should be applied to reduce the daily number of operating vehicles, and a central booking office should be set up in Bandar Lampung to simplify and speed up passenger booking. It is the responsibility of the operator or driver association to implement the proposed changes such that the intended improved efficiency can be achieved.

\section{References}

Arifianto, Y. 2003. The characteristics and performance of travel vehicles observed from the vehicle operating costs. Thesis, Department of Civil Engineering, Faculty of Engineering, University of Lampung (in Indonesian).

Arintono, S. 2008. Improving efficiency of motorcycle taxi operation: A case study in Bandar Lampung Indonesia. International Journal of Logistics and Transport 2(2): 25-30.

Arintono, S. 2003. Is the fare fair? A case study of Mikrolet operation in Bandar Lampung Indonesia. Journal of the Eastern Asia Society for Transportation Studies 5: 38-49.

Arintono, S. 2001. Assessing the fleet requirement: Public transport in medium sized Indonesian cities. Journal of the Eastern Asia Society for Transportation Studies 4(1): pp. 51-62.

Calter, J. 2006. The operating characteristics of travel vehicles on the route of Tanjung Karang-Bakauheni. Thesis, Department of Civil Engineering, Faculty of Engineering, University of Lampung (in Indonesian). 
Chandradewi. 2003. The analysis of queuing costs for air-conditioned buses on the route of Rajabasa-Bakauheni. Thesis, Department of Civil Engineering, Faculty of Engineering, University of Lampung (in Indonesian).

Tjikasan, L. 2003. The analysis of queuing costs for ordinary buses on the route of Rajabasa-Bakauheni. Thesis, Department of Civil Engineering, Faculty of Engineering, University of Lampung (in Indonesian).

\section{About the Author}

SUlistyo ARINTONO (sulistyo@eng.upm.edu.my) is a senior lecturer in the Department of Civil Engineering, Faculty of Engineering, Universiti Putra Malaysia. He holds an Ir. degree from the University of Gadjah Mada; an M.Eng. degree from the Asian Institute of Technology; and Ph.D. from the Institute for Transport Studies, University of Leeds. His research interests are public transport policy, regulation, management, and operation, with particular interest in paratransit operation in developing countries. 